\title{
Overweight and Obesity in Ahmedabad school going children: Magnitude in relationship to hypertension and associated risk factors
}

\author{
Bhoomi Arora*1, Snehal Patel ${ }^{2}$ \\ 'Department of Pharmacology, SAL Institute of Pharmacy, Ahmedabad, Gujarat, INDIA. \\ ${ }^{2}$ Department of Pharmacology, Institute of Pharmacy, Nirma University, Ahmedabad, Gujarat, INDIA.
}

\begin{abstract}
Introduction: India is undergoing a rapid epidemiological transition with increased urbanization and socio-economic development which has resulted in a dramatic change in lifestyle, consisting of physical inactivity, diet rich in fat, sugar and salt coupled with a high level of mental stress. Obesity is one of the most common diseases worldwide and the prevalence in school aged children appears to be increasing. Thus, the present study was planned to establish an association between body mass index (BMI) with hypertension and associated risk factors amongst school children in the age group of 12 to 17 years belonging to all socioeconomic group in Ahmedabad. Materials and Methods: A population based cross sectional study was conducted in the four schools of Ahmedabad. Using stratified random sampling method, 373 participants were selected. Body Mass Index (BMI) status and Blood Pressure (BP) were estimated using standard protocol and their various correlates regarding socio-demographic characteristics were looked into. Result: Prevalence of overweight and obesity was found to be $8.8 \%$ and $2.9 \%$ respectively. Prevalence of overweight and obesity was more prevalent among girls comparatively among boys. Overall prevalence of hypertension was $5.8 \%$. The prevalence of obesity among students was higher in upper and upper middle socioeconomic class as compared to middle and low socioeconomic class. Family history of diabetes and obesity were also found to be positively associated. Conclusion: Childhood obesity and hypertension were found to be common in the city of Ahmedabad which suggest the need for greater public awareness programs on these morbidities.
\end{abstract}

Key words: Overweight, Obesity, Children, Hypertension, Diet type, socioeconomic group.

\section{INTRODUCTION}

Developing countries like India is undergoing a rapid epidemiological transition with increased urbanization and socioeconomic development which has resulted in a dramatic change in lifestyle, consisting of physical inactivity, diet rich in fat, sugar and salt coupled with a high level of mental stress. This has led to increased incidence of lifestyle diseases like hypertension, type 2 Diabetes Mellitus, dyslipidemia, obesity and ischemic heart diseases. ${ }^{1}$

Obesity can be seen as the first wave of a defined cluster of non-communicable diseases called "New World Syndrome" creating an enormous socio-economic and public health burden in poorer countries. ${ }^{2}$ Obesity, overweight and hypertension in school children and adolescents are emerging as newer health problems in developing countries like India. The severity of obesity and age of onset affect the likelihood of persistence of obesity into adulthood and thus entrainment of obesity induced morbidities like pre-hypertension and hypertension. $^{3}$

Obesity has reached a pandemic proportion with more than 1 billion of them have grown up as adult overweight; of them nearly 300 million have been noted to be clinically obese. Adolescence, as considered by World Health Organization (WHO) as from 10 to 19 years, currently recorded a prevalence of $20 \%$ in UK and Austra-
DOI: 10.5530ijopp.10.1.9

Address for correspondence: Bhoomi Arora, Department of Pharmacology, SAL Institute of Pharmacy, Ahmedabad, Gujarat, INDIA.

Phone no: +91 9824847369 E-mail: arorabhoomi@gmail.com 
lia, $15.8 \%$ in Saudi Arabia, 15.6\% in Thailand, 10\% in Japan, and $7.8 \%$ in Iran. ${ }^{4}$

Although the growing prevalence of overweight and obesity among adolescent population has received much attention in the recent years, there is a dearth of data in India, partly because of the persisting high prevalence of under nutrition.

In the above scenario, this community based study was undertaken to find out the prevalence and correlates of overweight and obesity in school going students of Ahmedabad, Gujarat.

\section{MATERIAL AND METHOD}

A total of 373 school going students belonging to both sexes, 217 boys and 156 girls between 13 to 17 years were included in the study. The schools were selected by stratified random sampling method. Prior permission was obtained from all concerned. A pre-designed questionnaire to obtain information regarding socio-economic status, nutrition, physical activity, diet and family history of diabetes, obesity and hypertension was given to the subjects. Anthropometric data like, height measured with stadiometer and weight was measured with a digital weighing scale. BMI-for-age charts (Table1) were used to assess weight in relation to stature for children as recommended by Centres for Disease Control and Prevention (CDC), National Centre for Health Statistics (2005). Clinical examination of the subjects was carried out by taking their BP measurements. Before recording the $\mathrm{BP}$, the procedure was fully explained to the children and sufficient time was allowed for recovery from recent activity and apprehension. BP was recorded in sitting position in right arm by auscultatory method using a standard mercury sphygmomanometer with the subject seated and the arm extended over the table at the level of heart.

\section{RESULTS}

A total number of 373 students with age group between 12-17 years from different school were screened for their height, weight and body mass index. Out of 373 children 217 (58.1\%) were boys and 159 (41.8\%) were girls. However, these differences were not significantly different with respect to gender at any given age.

Prevalence of overweight and obesity and its relationships with socioeconomic status, physical activity, participation in sports and stress level is given in Table 1.

The overall prevalence of boys and girls having lower BMI were $33.1 \%$ and $23.7 \%$ respectively. The prevalence of boys and girls having normal BMI were $56.2 \%$ and $62.8 \%$ respectively. The prevalence of overweight was $7.8 \%$ among boys and $10.2 \%$ among girls. Prevalence of obesity was $2.9 \%$ in boys and $1.5 \%$ in girls. The prevalence of underweight is $2.7 \%$ in boys and $3.2 \%$ in girls (Figure $1 \& 2$ ). There was also a higher prevalence of overweight and obesity in girls compared with boys, but difference was not significant.

Prevalence of systolic hypertension and diastolic hypertension was $9.1 \%$ and $7.2 \%$ respectively. It was observed that the prevalence of systolic hypertension was higher in overweight and obese group compared to underweight and healthy group. Whereas prevalence of diastolic hypertension as well as hypertension was

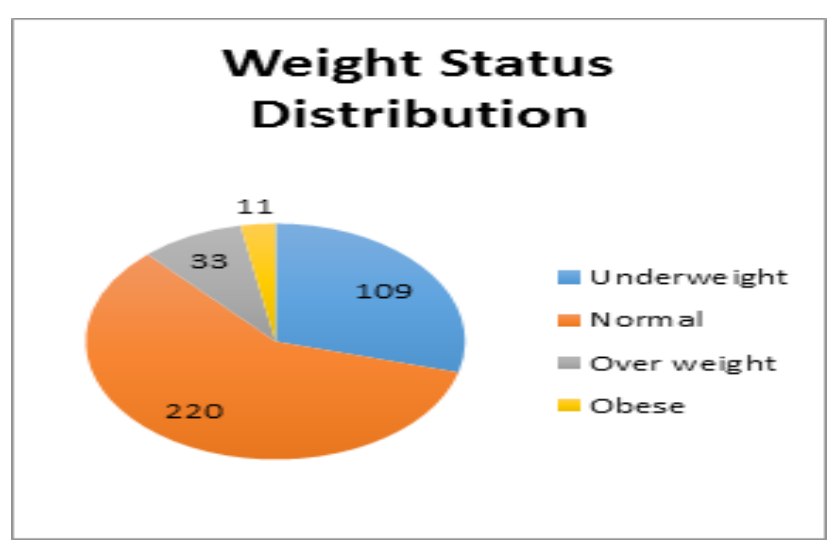

Figure 1: Weight Status Distribution among School going children.

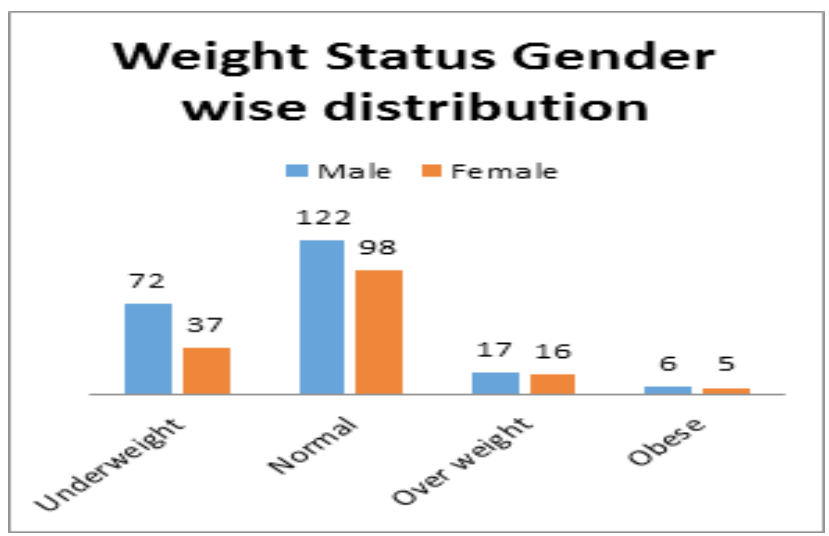

Figure 2: Gender wise distribution of weight Status.

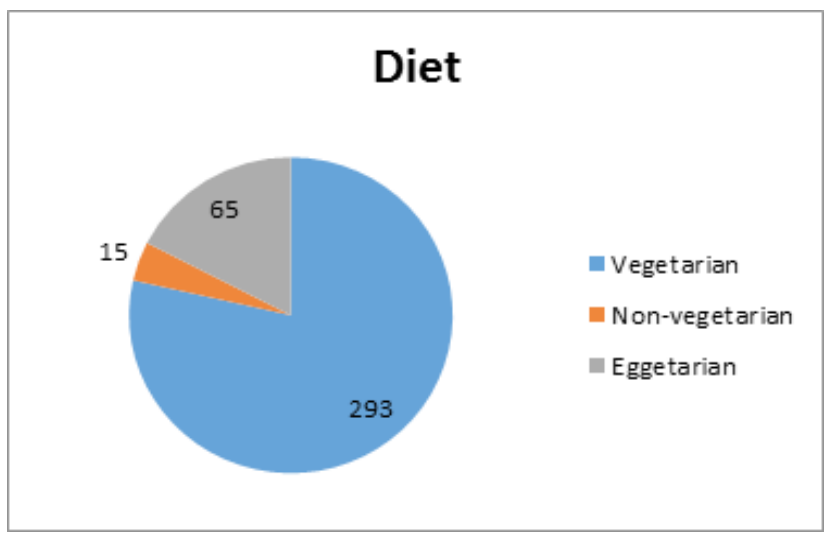

Figure 3: Type of diet among school going children. 


\section{Table 1: Distribution of school children according to their BMI}

\begin{tabular}{|c|c|c|c|c|c|}
\hline & Under weight & Healthy Weight & Overweight & Obese & TOTAL \\
\hline \multicolumn{6}{|l|}{ Blood Pressure } \\
\hline \multirow[t]{2}{*}{ Systolic BP (more than 140) } & 2 & 23 & 6 & 3 & 34 \\
\hline & $(1.8 \%)$ & $(10.4 \%)$ & $(18.8 \%)$ & $(27.2 \%)$ & $(9.1 \%)$ \\
\hline \multirow[t]{2}{*}{ Diastolic BP (more than 90) } & 3 & 20 & 3 & 1 & 27 \\
\hline & $(2.7 \%)$ & $(9 \%)$ & $(9 \%)$ & $(3.7 \%)$ & $(7.2 \%)$ \\
\hline \multirow[t]{2}{*}{ Both BP high } & 2 & 15 & 3 & 1 & 21 \\
\hline & $(1.8 \%)$ & $(6 \%)$ & $(9 \%)$ & $(4.7 \%)$ & $(5.6 \%)$ \\
\hline \multicolumn{6}{|l|}{ Physical Activity } \\
\hline \multirow[t]{2}{*}{ Participate in Exercise } & 102 & 202 & 33 & 11 & 348 \\
\hline & $(93.5 \%)$ & $(91.8 \%)$ & $(100 \%)$ & $(3.1 \%)$ & $(93.2 \%)$ \\
\hline \multirow[t]{2}{*}{ Play Indoor game } & 16 & 37 & 2 & 1 & 56 \\
\hline & $(14.6 \%)$ & $(16.8 \%)$ & $(6 \%)$ & $(1.7 \%)$ & $(15 \%)$ \\
\hline \multirow[t]{2}{*}{ Play Outdoor game } & 69 & 122 & 14 & 6 & 211 \\
\hline & $(63.3 \%)$ & $(55.4 \%)$ & $(42.2 \%)$ & $(18.1 \%)$ & $(56.6 \%)$ \\
\hline \multirow[t]{2}{*}{ Play game on mobile/laptop } & 109 & 218 & 33 & 11 & 371 \\
\hline & $(100 \%)$ & $(99 \%)$ & $(100 \%)$ & $(100 \%)$ & $(99.4 \%)$ \\
\hline \multicolumn{6}{|l|}{ Family history of disease } \\
\hline \multirow[t]{2}{*}{ Diabetes } & 21 & 77 & 11 & 3 & 112 \\
\hline & $(19.2 \%)$ & $(35 \%)$ & $(33.3 \%)$ & $(27.2 \%)$ & $(30 \%)$ \\
\hline \multirow[t]{2}{*}{ Obesity } & 21 & 42 & 13 & 4 & 80 \\
\hline & $(19.2 \%)$ & $(19 \%)$ & $(39.3 \%)$ & $(36.3 \%)$ & $(21.4 \%)$ \\
\hline \multirow[t]{2}{*}{ Hypertension } & 14 & 42 & 11 & 3 & 70 \\
\hline & $(12.8 \%)$ & $(19 \%)$ & $(33.3 \%)$ & $(27.2 \%)$ & $(18.7 \%)$ \\
\hline \multicolumn{6}{|l|}{ Junk food Habit } \\
\hline \multirow[t]{2}{*}{ Everyday } & 18 & 51 & 7 & 2 & 78 \\
\hline & $(16.5 \%)$ & $(23.1 \%)$ & $(21.2 \%)$ & $(18.1 \%)$ & $(20.9 \%)$ \\
\hline \multirow[t]{2}{*}{ Once in a week } & 62 & 106 & 18 & 5 & 191 \\
\hline & $(56.8 \%)$ & $(48.1 \%)$ & $(54.5 \%)$ & $(45.4 \%)$ & $(51.2 \%)$ \\
\hline \multirow[t]{2}{*}{ Once in fifteen days } & 16 & 37 & 6 & 2 & 61 \\
\hline & $(14.6 \%)$ & $(16.8 \%)$ & $(18.1 \%)$ & $(18.1 \%)$ & $(16.3 \%)$ \\
\hline \multirow[t]{2}{*}{ Once in a month } & 13 & 26 & 2 & 2 & 43 \\
\hline & $(11.9 \%)$ & $(11.8 \%)$ & $(6 \%)$ & $(18.1 \%)$ & $(11.5 \%)$ \\
\hline \multicolumn{6}{|l|}{ Sweet/chocolate eating Habit } \\
\hline \multirow[t]{2}{*}{ Everyday } & 47 & 87 & 11 & 4 & 149 \\
\hline & $(43.1 \%)$ & $(39.5 \%)$ & $(33.3 \%)$ & $(36.3 \%)$ & $(39.9 \%)$ \\
\hline \multirow[t]{2}{*}{ Once in a week } & 41 & 80 & 14 & 4 & 139 \\
\hline & $(37.6 \%)$ & $(36.3 \%)$ & $(42.4 \%)$ & $(36.3 \%)$ & $(37.2 \%)$ \\
\hline \multirow[t]{2}{*}{ Once in fifteen days } & 11 & 32 & 5 & 3 & 51 \\
\hline & $(10 \%)$ & $(14.5 \%)$ & $(15.1 \%)$ & $(27.2 \%)$ & $(13.6 \%)$ \\
\hline Once in a month & 10 & 21 & 3 & 0 & 34 \\
\hline & $(9.1 \%)$ & $(9.5 \%)$ & $(9 \%)$ & & $(9.1 \%)$ \\
\hline Stress Level & & & & & \\
\hline Good control over stress & 82 & 154 & 21 & 6 & 263 \\
\hline & $(75.2 \%)$ & $(70 \%)$ & $(63.6 \%)$ & $(54.5 \%)$ & $(70.5 \%)$ \\
\hline Less level of stress & 25 & 60 & 11 & 5 & 101 \\
\hline & $(22.9 \%)$ & $(27.2 \%)$ & $(33.3 \%)$ & $(45.4 \%)$ & $(27 \%)$ \\
\hline Medium level of stress & 1 & 5 & 1 & 0 & 7 \\
\hline & $(0.9 \%)$ & $(2.2 \%)$ & $(3 \%)$ & & $(1.8 \%)$ \\
\hline
\end{tabular}




\begin{tabular}{|c|c|c|c|c|c|}
\hline Very high level of stress & $\begin{array}{c}1 \\
(0.9 \%)\end{array}$ & $\begin{array}{c}1 \\
(0.4 \%)\end{array}$ & 0 & 0 & $\begin{array}{c}2 \\
(0.5 \%)\end{array}$ \\
\hline \multicolumn{6}{|l|}{ Socioeconomic Status } \\
\hline \multirow[t]{2}{*}{ Upper (I) } & 4 & 5 & 2 & 1 & 12 \\
\hline & $(3.6 \%)$ & $(2.2 \%)$ & $(6 \%)$ & $(9 \%)$ & $(3.2 \%)$ \\
\hline \multirow[t]{2}{*}{ Upper middle (II) } & 36 & 77 & 8 & 4 & 125 \\
\hline & $(33 \%)$ & $(35 \%)$ & $(24.2 \%)$ & $(36.3 \%)$ & $(33.5 \%)$ \\
\hline \multirow[t]{2}{*}{ Middle / Lower middle (III) } & 49 & 96 & 19 & 4 & 168 \\
\hline & $(44.9 \%)$ & $(43.6 \%)$ & $(57.5 \%)$ & $(36.3 \%)$ & $(45 \%)$ \\
\hline \multirow[t]{2}{*}{ Lower / Upper lower (IV) } & 20 & 42 & 4 & 2 & 68 \\
\hline & $(18.3 \%)$ & $(19 \%)$ & $(12.1 \%)$ & $(18.1 \%)$ & $(18.2 \%)$ \\
\hline Lower (V) & 0 & 0 & 0 & 0 & 0 \\
\hline
\end{tabular}

*Values are in absolute no. \& percentage

higher in overweight children compared to healthy children but the prevalence of diastolic hypertension and hypertension was almost similar in obese children to healthy children.

Irrespective of weight status category almost all students participate in exercise and play on laptop/mobile. While prevalence of participate in indoor and outdoor game is lower in overweight and obese children compared to healthy weight children.

Out of 373 students, $78.5 \%$ were vegetarian, $4 \%$ were non-vegetarian and $17.4 \%$ were eggetarian (Figure 3). Vegetarian diet, non-vegetarian or eggetarian diet did not have any effect on prevalence of underweight, overweight and obesity. In present study irrespective of weight status we found equal prevalence for junk food, sweets/chocolate eating habits and stress level.

Family history of diabetes and obesity is independently associated with BMI. Children having family history of obesity were more likely to have more prevalence of obesity and overweight than those having family history of diabetes. The prevalence of family history of hypertension was high in overweight and obese students than that of healthy weight.

The prevalence of obese among children was high in upper and upper middle socioeconomic class as compared to lower middle socioeconomic class group. Furthermore prevalence of overweight was the highest in the upper middle socioeconomic class. Thus, socioeconomic status was related to children's risks of being obese or overweight.

high than overweight and obese among school going children. The present study showed that the overall prevalence of overweight was $8.8 \%$ among children, $7.8 \%$ in boys, $10.2 \%$ in girls. While the overall prevalence of obesity was $2.9 \%$, from that $2.7 \%$ were boys and 3.2\% were girls. Sonal Sureshbhai Gamit et al. in reported prevalence of overweight $10.2 \%$ and obesity
$6 \%$, in Surat city. The prevalence of overweight and obesity was $12.4 \%$ and $8.2 \%$ in boys whereas it was $7.2 \%$ and $2.7 \%$ in girls. ${ }^{5}$ These data suggests high prevalence of overweight and obesity is high in Surat city compared to Ahmedabad. Our results for prevalence of overweight is lower than reported by Ravikumar et al. in Karnataka, ${ }^{6}$ Goyal et al. ${ }^{7}$ and Jugesh Chattwal et al $(14.2 \%) .^{8}$ Krutarth et al. conducted study on students of Ahmedabad aged 11 to 19 years and reported 13.3\% prevalence of overweight and $5.4 \%$ of obesity.

Elevated blood pressure, systolic or diastolic at any age, in either sex is a contributor for all forms of cardiovascular disease. ${ }^{10}$ There is plenty of evidence to suggest that hypertension begins in childhood and adolescence. ${ }^{11-13}$ The asymptomatic nature of hypertension in early phases of its onset during adolescence increases the chances of developing complications during adulthood. ${ }^{14}$ Prevalence of hypertension in the present study was found to be more significant in overweight and obese children as compared to healthy weight children. This relationship has been reported by other studies in India. ${ }^{15-18}$

Sedentary behaviour and physical activity in children maybe predictive of body mass in late adolescence. Decreased sports and exercise have also been implicated in childhood obesity because they reduce resting metabolism results in reduction of physical activity. A change in the volume of daily physical activity may account for imbalance between energy intake and energy expenditure. Due to unsafe roads, lack of free space for playing and increased television viewing, computer games and internet use has made life sedentary which overemphasis on academic excellence, unscientific urban planning and ever-increasing automated transport. ${ }^{19,20}$ In present study we found that overweight and obese students' participation in indoor as well as outdoor games is less compare to others while irrespective of weight status almost all category of students play games on mobile or 
computer and watch television every day. Our results are in support to the study conducted by Goyal RK et al. ${ }^{7}$

Questions about type of diet either vegetarian, nonvegetarian or eggetarian, frequency of eating junk food either daily or once in a week or month, and habit of eating sweets or chocolates provide information about diet and lifestyle. Diet and lifestyle are ostensibly major contributors to weight problems and varies with different SES especially countries like India. Overweight and obesity are strongly associated with certain types of diets, such as those that include large amounts of fats, animal-based foods and processed foodstuffs. ${ }^{20}$ Food in urban area has been replaced by high calorie snacks and junk food. ${ }^{21}$ In present study we focused our analysis on type of diet, habit of junk food and chocolate eating habit because they play important roles in obesity. We found that majority of overweight and obese students were vegetarian. Junk food eating habit has positive relation with prevalence of overweight and obesity. These results correlate well with previous reports which suggest that junk food (bakery items, pizza, burger, cheese, butter, oily items) chocolate intake tends to be more common among overweight and obese adolescents than among normal-weight adolescents. ${ }^{22,23}$

Prevalence of overweight and obesity are more in children with family history of diabetes and obesity. ${ }^{24}$ In the present study we found that family history of diabetes, obesity and hypertension were positive for overweight and obese students than healthy weight. This indicates that children having positive family history of diabetes, obesity and hypertension are more likely to become obese or over weight and chances of diabetes and hypertension are high at early age.

In modern society, where over nutrition, sedentary lifestyle, and sleep deprivation are typical traits, chronic exposure to environmental stress potentially contributes to the development ofobesity. ${ }^{25}$ But in present study we found that irrespective of weight status almost all students found to have no stress or less level of stress.

Kuppuswamy's socioeconomic status is an important tool in hospital and community based research in India. It was proposed in $1976 .{ }^{26}$ This scale takes account of education, occupation, and income of the family to classify study groups in to high, middle and low socioeconomic status. As pointed out rightly by Mishra and Singh $^{27}$ and later from Rewa $e a^{28}{ }^{28}$, we have used the latest revision based on price revision. In present study we found high prevalence of obesity in upper and upper middle socioeconomic class while high prevalence of overweight in middle socioeconomic class. Our data suggest that the prevalence of overweight and obesity varied remarkably with difference in socioeconomic sta- tus development levels, this was associated with life style and dietary management.

\section{CONCLUSION}

In conclusion, the crisis of both childhood obesity and elevated blood pressure is global and is steadily affecting many low and middle income countries, particularly in urban settings. The prevalence has increased at an alarming rate globally. In present study, elevated blood pressure was seen in high percentages in students with overweight and obesity when compared with children healthy students. Current lifestyle methods like physical inactivity, unhealthy eating habits like junk food are the major causative factors for this increasing trend in urban area. These trends are disturbing and call for concerted efforts targeted at improving lifestyles of children and adolescents. So in feature to prevent morbidities of obesity such as hypertension, early intervention strategies for promoting healthy eating, physical activities and health education should be undertaken from school age group.

\section{ACKNOWLEDGEMENT}

We are grateful to the participants and Dr. Kamlesh Naik who took part in the survey. We are also thankful to the principal of schools who allowed us to conduct study in their school. We are thankful to Gujarat Council of Science and Technology (GUJCOST) for proving financial support in terms of minor research grant.

\section{CONFLICT OF INTEREST}

None

\section{ABBREVIATION USED}

BMI: Body Mass Index; CDC: Centres for Disease Control and Prevention.

\section{REFERENCES}

1. Mohan V. Why Are Indians More Prone to Diabetes.Journal of Association of Physicians of India. 2004;52:468-74. PMid:15645957.

2. World Health Organization. Obesity: preventing and managing the global epidemic. Technical Report Series No. 894, Geneva: WHO; 2000.

3. Dietz WH, Bandini LG, Gortmaker S. Epidemiologic and metabolic risk factors for childhood obesity. Prepared for Fourth congress on Obesity Research, Austria. Klin Pediatr. 1998;202(2):69-72. http://dx.doi.org/10.1055/s-2007-1025490 PMid:2182935.

4. Arya SN, Kumar R. Obesity. Indian Acad Clin Med. 2004;5:166-81.

5. Sureshbhai GS, Moitra M, Verma MR. Prevalence of obesity and overweight in school going adolescents of Surat city, Gujarat, India. Int J Med Sci Public Health. 2015;4(1):42-7

6. Baradol RV, Patil S, Ranagol A. Prevalenceof overweight, obesity and hypertension amongst school childrenand adolescents in North Karnataka: A 
cross sectional study. Int J Med Public Health. 2014;4(3):260-4. http://dx.doi. org/10.4103/2230-8598.137713.

7. Goyal RK, Shah VN et al. Prevalence of Overweight and Obesity in Indian Adolescent School Going Children: Its Relationship with Socioeconomic Status and Associated Lifestyle Factors. JAPI. 2010; 58:151-158 PMid:20848812.

8. Chhatwal $\mathrm{J}$, Verma $\mathrm{M}$ et al. Obesity among pre-adolescent and adolescents of a developing country (India). Asia Pac J Clin Nutr. 2004;13(3):231-5. PMid:15331333.

9. Krutarth B, Umesh O. Obesity among adolescents of ahmedabad city, gujarat, india- a community based cross-sectional study. Int J Biol Med Res. 2012;3(2):1554-7

10. Kannel WB. Role of blood pressure in cardiovascular diseasesTheFramingham study. Angiology. 1975,26(1):1-14. http://dx.doi. org/10.1177/000331977502600101 PMid:1122043.

11. de Man SA, André JL, Bachmann H, Grobbee DE, Ibsen KK, Laaser $\mathrm{U}$, et al. Blood pressure inchildhood: Pooled findings of six European studies. J Hypertens. 1991;9(2):109-14. [PubMed: 1849524] http://dx.doi. org/10.1097/00004872-199102000-00002 PMid:1849524.

12. Uhari M, Nuutinen EM, Turtinen J, Pokka T, Kuusela V, Akerblom HK, et al. Blood pressure in children, adolescents and young adults. Ann Med. 1991;23(1):4751. [PubMed: 2036205] http://dx.doi.org/10.3109/07853899109147930 PMid:2036205

13. Yong LC, Kuller LH, Rutan G, Bunker C. Longitudinal study of blood pressure: Changes and determinants from adolescence to middle age. The Dormont High School follow up study. 19571963to19891990.

14. Am J Epidemiol. Khan MI, Lala MK, Patil R, Mathur HN, Chauhan NT. A Study of the Risk Factors and the Prevalenceof Hypertension in the Adolescent School Boys of Ahmedabad City. [Last cited 2010 Dec 20];J Clin DiagnRes [Serial Online] 2010 4:3348-54. 1993;138:973-83. [PubMed: 8256782]6.

15. Verma M, Chhatwal J, George SM. Obesity and hypertension in children. Indian Pediatr. 1994;31(9):1065-9. PMid:7883362.

16. Mohan B, Kumar N, Aslam N, Rangbulla A, Kumbkarni S, Sood NK, et al. Prevalence of sustained hypertension and obesity in urban and rural school going children in Ludhiana. Indian Heart J. 2004;56(4):310-14. PMid:15586739.
17. Anand NK, Tandon L. Prevalence of hypertension in school going children. Indian Pediatr. 1996;33:377-81. PMid:9005224.

18. Gupta AK, Ahmad AJ. Childhood obesity and hypertension. Indian Pediatr. 1990;27:333-7. PMid:2210818.

19. Bar-Or O, Foreyt J, Bouchard C, Brownell KD, Dietz WH, Ravussin E, et al. Physical activity, genetic, and nutritional considerations in childhood weight management. Med Sci Sports Exerc. 1998;30(1):2-10. http://dx.doi. org/10.1097/00005768-199801000-00002PMid:9475638.

20. Chopra M, Galbraith S, Darnton-Hill I. A global response to a global problem: the epidemic of over nutrition. Bull World Health Organ. 2002;80(12):952-8. PMid:12571723.

21. Bhave S, Bavdekar A, Otive M. IAP National task force for childhood prevention of adult disease: Childhood obesity. Indian Paediatr. 2004;41:559-75 PMid:15235162.

22. Klesges RC, Klesges LM, Eck LH, Shelton ML. A longitudinal analysis of accelerated weight gain in preschool children. Pediatrics. 1995;95:126-30. PMid:7770289.

23. Wolfe WS, Campbell CC, Frongillo Jr EA, Haas JD, Melnik TA. Overweight schoolchildren in New York State: prevalence and characteristics. Am J Public Health. 1994;84(5):807-13. http://dx.doi.org/10.2105/ AJPH.84.5.807PMid:8179053 PMCid:PMC1615049.

24. Sinha R, Fisch G, Teague B, etal. Prevalence ofimpaired glucose tolerance among children and adolescents with marked obesity. N Engl J Med. 2002;346(11):80210. http://dx.doi.org/10.1056/NEJMoa012578PMid:11893791.

25. Mousumi B, Blanca O, Blandine L. Stress and obesity: the role of the hypothalamic-pituitary-adrenal axis in metabolic disease. Curr Opin Endocrinol Diabetes Obes. 2009;16(5):340-6. http://dx.doi.org/10.1097/ MED.0b013e32832fa137PMid:19584720 PMCid:PMC2858344.

26. Kuppuswamy B. Delhi: Manasayan; 1981. Manual of socioeconomic status (Urban) p. 8.

27. Mishra D, Singh HP. Kuppuswamy's socioeconomic status scale: A revision. Indian J Pediatr. 2003;70:273-4. http://dx.doi.org/10.1007/ BF02725598PMid:12785303.

28. Kumar N, Shekhar C, Kumar P, Kundu AS. Kuppuswamy's socioeconomic status scale updating 2007. Indian J Pediatr. 2007;74:1131. PMid:18174655. 